\title{
Letters
}

All letters are subject to editing and may be shortened. General letters can be sent to bjgpdisclarcgp.org.uk (please include your postal address for publication), and letters responding directly to BJGParticles can be submitted online via eLetters. We regret we cannot notify authors regarding publication.

For submission instructions visit: bjgp.org/letters

\section{Editor's choice}

There is no evidence that time spent in general practice as a UK medical student correlates with recruitment to the GP workforce. In fact, the study by Harding et al shows that the correlation is in the opposite direction. ${ }^{1}$ As Harding et al point out, there was a substantial increase in the proportion of medical school training spent in general practice between 1980 and 2002. Although they document a more recent decline, the current proportions of medical school curricula allocated to general practice are 4-5 times greater than they were in 1980. The UK Medical Careers Research Group reported that proportions of UK graduates entering general practice from cohorts qualifying in the 1970s and early 80 s had ranged between $40-45 \%$ : among 1983 graduates the proportion working in general practice was $42.7 \%$ 10 years after qualification. ${ }^{2}$ The current dire recruitment figures show that the proportion choosing general practice is less than half what it was in the 1970s and 80s, when there was effectively no general practice in the curriculum.

It would be absurd to suggest that greater exposure to general practice in medical school caused the decline in proportion of graduates choosing the specialty, but it is no more absurd than claiming that further increasing the proportion of undergraduate curriculum time in general practice will help attract $50 \%$ of graduates into general practice. Only significant changes to the rewards and opportunities in primary care can do that.

Tim Lancaster,

GP, Oxford and Director of Clinical

Studies, Oxford Medical School.

E-mail: tim.lancasterlamedsci.ox.ac.uk

\section{REFERENCES}

1. Harding A, Rosenthal J, Al-Seaidy M, et al. Provision of medical student teaching in UK general practices: a cross sectional study. $\mathrm{Br} \mathrm{J}$ Gen Pract 2015; DOI: 10.3399/bjgp15X685321

2. Lambert TW, Evans J, Goldacre MJ.

Recruitment of UK trained doctors into general practice: findings from national cohort studies. Br J Gen Pract 2002; 52(478): 364-372.

DOI: 10.3399/bjgp15X68556

\section{Continuity of care is very important}

We congratulate Ridd et al on an interesting approach to cancer diagnosis in general practice, but were disappointed that in 2015 they could write:

Seeing the same doctor is associated with higher patient satisfaction but evidence that it makes a difference to patient outcomes is weak.

Patient satisfaction is itself a major patient outcome, not something separate.

Prospective randomised trials in this field can be unethical, so that much of the available evidence is observational. However, two randomised controlled trials have been done and both were positive for continuity of care. ${ }^{2,3}$

Numerous international studies reveal that continuity of generalist care is significantly associated with better compliance, better care for people with diabetes, the development of trust in medical generalists by patients, provision of more personal preventive care, significantly fewer hospital admissions for elderly ambulatory care, and lower all-cause mortality. The large number of studies reported are not in equipoise, there are several with no definite result, but about 100 with a positive association, and only three, including Ridd et al, ${ }^{1}$ with an adverse effect.

On the balance of probabilities, continuity of generalist care is beneficial to patients, and both patients and clinicians deserve to hear that message.

Denis Pereira Gray,

Emeritus Professor, St Leonard's Research Practice, Exeter.

E-mail: denis.pereiragraylabtinternet.com

Kate Sidaway-Lee,

Research Assistant, St Leonard's Research Practice, Exeter.

Eleanor White

Student on BSc course, Exeter Medical School, Exeter.
Philip Evans,

Managing Partner and Research Lead, St Leonard's Research Practice, Exeter.

\section{REFERENCES}

1. Ridd MJ, Ferreira DL, Montgomery AA, et al. Patient-doctor continuity and diagnosis of cancer: electronic medical records study in general practice. Br J Gen Pract 2015; DOI: 10.3399/bjgp15X684829.

2. Wasson JH, Sauvigne AE, Mogielnicki RP, et al. Continuity of outpatient medical care in elderly men. A randomized trial. JAMA 1984; 252(17): 2413-2417.

3. Flint C, Poulengeris A, Grant A. The 'Know Your Midwife' Scheme: a randomised trial of care by a team of midwives. Midwifery 1989; 5(1): 11-16.

\section{DOI: 10.3399/bjgp15X685573}

\section{The inevitable demise of the independent contractor status}

Azeem Majeed and Naureen Bhatti make a compelling case for giving up independent contractor status, while Rebecca Rosen suggests that this would result in some wins', but would not be worth the disruption that enforcing it would cause. In fact no enforcement is necessary. The inevitable demise of independent contractor status is already being facilitated by our profession.

Roger Jones rightly points out that many GPs are opting for salaried roles. Uncertainty over the future of general practice combined with inflated fears of the responsibilities of partnership undoubtedly play a role in this choice, but for many young GPs a salaried assistantship is the only employment option on offer. In an increasingly difficult economic climate, partnerships are replacing partners with assistants not to meet the needs of the next generation of GPs, but as the only means they have of maintaining or increasing the incomes of the remaining partners. However, subsidising partners' incomes from the lower pay of assistants is an uncoupling from economic reality that can have only one consequence.

The government's intention to make general practice a 7-day service is both 
good for patients and a tool for promoting practice federation, the key to modernising primary care. Combining this with a clamp on primary care funding appears illogical but ensures that more and more partners will be replaced by assistants until partnerships become neither viable nor identifiable. When partners themselves demand a salaried service, no doubt to be managed by private healthcare providers, they will be surprised that the money on offer will be based on the average salary of an assistant, not that of a partner. In the interests of self-preservation, they will have extracted all the gold from the 'golden era'.

The small business model may seem to serve a dwindling elite of general practice partners but no longer serves the interests of patients or today's young doctors. It should be abandoned while our leaders are still in a position to negotiate terms.

Alan Charles Dellow,

Retired GP Partner, Amersham, and Medical Education Adviser, Ramathibodi Hospital Medical School, Bangkok, Thailand.

E-mail: alan.dellowabtinternet.com

\section{REFERENCE}

1. Jones R, Majeed A, Bhatti N, et al. Should general practice give up the independent contractor status? Br J Gen Pract 2015; DOI: 10.3399/ bjgp15X685441.

DOI: 10.3399/bjgp15X685585

\section{Patient co-payments for general practice}

I was pleased to see the taboo topic of patient co-payments being discussed, although it is interesting that the two health systems discussed were Antipodean destinations for emigrant GPs, rather than the many successful European health systems, including Holland and France, that include such payments.

We are missing something in the UK by not enabling patients to contribute towards the cost of accessing the front door of the NHS - GPs. The talk about access is admirable, but why not capture some of the benefit of this to patients and employees by allowing GPS to offer co-payments for extended hours, online pre-booking, and untriaged urgent appointments? It is wrong that a self-employed plasterer, for example, has to take time off to get an urgent appointment, but this is the reality of a stressed system with funding derived from one source only. Allowing this patient to book a timely yet convenient appointment with a co-payment is obviously beneficial, and can bring in more money than it costs to provide. Similarly, employers may offer to pay for this service for their employees. Bringing in more finances to NHS GP practices in this way would support, rather than undermine, free-at-the-point-of-use GP care for the population.

The oft-misused example of aeroplanes can be useful in this case. All those on a flight arrive at the same destination, captained by the same trained pilot, and equally safe, yet some pay more for convenience and facilities. Of course, if a plane is not going to be safe due to funding, equipment, and staff shortages the flight is cancelled; yet in a centrally-underfunded NHS we soldier on, despite the risks to patients and staff.

\section{Simon Gilbert,}

GP Partner, South London .

E-mail: simongilbertadoctors.net.uk

\section{REFERENCE}

1. Toop L, Jackson C. Patient co-payment for general practice services: slippery slope or a survival imperative for the NHS? Br J Gen Pract 2015; DOI: 10.3399/bjgp15X685105.

DOI: 10.3399/bjgp15X685597

\section{Tools of the Trade}

This year and last, all graduating Scottish medical students have received a copy of Tools of the Trade, a small book of poetry designed to serve as a supportive companion as they begin their work as doctors and produced in conjunction with the Scottish

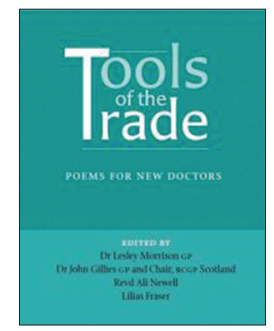

Poetry Library lwww.scottishpoetrylibrary. org.uk). ${ }^{1}$ It was devised initially in memory of Dr Pat Manson, a wonderful GP and educator, who died 3 years ago.

The first edition received very positive feedback and we are now in the process of creating a second edition for next year and beyond, and would be pleased to receive suggestions for poems. They need to speak to the experience of being a junior doctor and to be short. They could be written by well-known poets, by lesser-known poets, or by yourself!

Please submit your suggestions to Kate Hendry (likenapnonecoop.coop) by the end of July. We look forward to hearing from you

Lesley Morrison,

GP, Scottish Borders.

E-mail: lesleylaljmorrison.fsnet.co.uk

John Gillies,

Chair RCGP Scotland 2010-2014.

\section{REFERENCE}

1. Morrison L, Gillies J, Newell A, Fraser L, eds. Tools of the trade: poems for new doctors. Edinburgh: Scottish Poetry Library, 2014.

DOI: 10.3399/bjgp15X685609

\section{Correction}

In the printed version of the May 2015 article by Tran $\mathrm{V}$-T, et al. Impact of a printed decision aid on patients intention to undergo prostate cancer screening: a multicentre, pragmatic randomised controlled trial in primary care. Br J Gen Pract 2015; DOI: 10.3399/ bjgp15X684817 (abridged text, in print: Br J Gen Pract 2015; 65: 236-237), the summary box incorrectly stated: A simple, printed decision aid about prostate cancer was shown in a randomised controlled trial to increase patients' intentions to undergo screening. Whereas it should have stated 'A simple, printed decision aid about prostate cancer was shown in a randomised controlled trial to increase informed decision making and reduce their intention to undergo screening'. We apologise for this error. The online version of the article is correct. DOI: 10.3399/ bjgp15X685945. 